\title{
Small-Scale Use of Solar Power in Remote, Developing Regions:
}

\author{
A Case Study \\ Mr. Brian Osende, Dr. John Abraham (Corresponding author) \& Dr. Greg Mowry \\ School of Engineering, University of St. Thomas \\ 2115 Summit Ave, St. Paul, MN 55105-1079, USA
}

Tel: 1-651-962-5766 E-mail: jpabraham@stthomas.edu

Received: February 23, 2011

Accepted: March 13, 2011

doi: $10.5539 /$ jsd.v4n3p3

The research was financed Xcel Energy and by the University of St. Thomas

\begin{abstract}
A solar-power-based electrical system was designed to provide power to a small, remote village in Western Uganda. The purpose of the project was to electrify the village by providing lighting and electrical outlets for use with small electronic devices. The size of the village (fifty homes, one school, and one pharmacy) allowed a centrally positioned solar-battery system that was directly wired to the houses. The system was designed in a modular manner so that redundancy could be achieved and security was improved; the system would continue to function after the loss of a portion of the solar-charging station.

The entire system required eight solar panels, each capable of producing $175 \mathrm{~W}$ in full sunlight. The panels were used to charge two $12 \mathrm{~V}$ batteries which were connected in series to produce $24 \mathrm{~V}$ of DC power. The batteries, which were charged during daytime, are discharged at night when power is utilized by the village. To improve the process by which energy is transferred to the batteries, a Maximum Power Point Tracking system (MPPT) was used. Inverters were instituted to transform the DC power from the batteries to $240 \mathrm{~V}$ AC power for transmission.

Following the successful implementation of the system, an education program was instituted to ensure proper maintenance of the system in the coming years. Plans are already underway to ensure that periodic replacement of certain components (e.g. batteries) is accomplished to ensure that the system is able to continue to provide electricity for years to come.
\end{abstract}

Keywords: Rural power development, Solar-power systems, Renewable energy, Sustainably development

\section{Introduction}

In many regions of the world, limited access to electricity is a critical factor which limits economic growth and access to social benefits such as health care and commerce. In many nations, a priority is given toward the distribution of electrical power to industrial centers which rely upon electricity for their operation. In these situations, access of electricity to residences is delayed or non-existent.

In some situations, grid-based power is physically available for residences yet often, the cost of electricity is outside the means of most inhabitants. This situation again results in limited or no electricity for residences. As a consequence, approximately $5 \%$ of Ugandan residents have reliable access to electricity, with rates in the rural part of the country far lower than this national average (Wolde-Rufeal, 2006; Sprei, 2002).

There are a variety of benefits which can be achieved if electricity is supplied to residences and small shopping regions. First, electrical lighting extends the work day and allows merchants longer time periods to sell their goods. Second, internal lighting provides students the opportunity to study after sunset. Third, lighting enables important operations such as pharmacies to extend their hours and improve service to the community. Fourth, lighting improves the security and reduces crime which occurs after nightfall. Finally, villages with lighting have a greater sense of community than those without and investment in the community is increased. These factors, among others, motivated the design, fabrication, and testing of a solar-powered battery-storage system which can be used to provide power to an entire village which is located in a remote region of Western Uganda. A summary of power usage and its connection to poverty rates in Africa is provided by (Karekezi, 2002; Davidson, 2003). 
The goals of the project were to provide lighting to all buildings in the village, provide a limited number of electrical outlets for small electronic devices, and work with the residents to ensure that the system would be sustainable far into the future. A secondary goal is to reduce the costs borne by local residents for their current electrical consumption (Kammen, et al., 2008)

Prior investigations have shown a correlation between electrical usage and economic growth rate (Wolde-Rufeal, 2006). While the correlation in some African countries is not a strict relation (in some cases, increased electrical consumption occurred with decreased economic growth), this occurrence is rare. It also reflects the reality that electricity is a very small portion of total energy usage in Africa; electricity accounts for approximately $5 \%$ of energy in the least developed parts of this continent (Wolde-Rufeal, 2006).

The importance of electrification of rural Uganda has been identified by international and national organizations. For instance, a cooperative project involving the World Bank, the Global Environment Facility, and the Ugandan Ministry of Energy has lead to a rural electrification plan. Among the goals of this plan is the creation of electrification investments in rural regions of Uganda (Kaijuka, 2006).

The region selected for this prototype case study was the village of Kitembe which is located in the Ntungamo District of Western Uganda. The village is near the Rwandan, Congolese, and Tanzanian borders and is six hours (by road) from the capital of Uganda (Kampala).

\subsection{Power Production Alternatives}

There are a number of potential of power sources available in the targeted village, Kitembe. Among them are hydro, solar, wind, biomass, and diesel. Some of these potential power sources were quickly eliminated during the design process. For instance, diesel was found to not be a viable alternative because of the high costs of diesel fuel. Furthermore, the village was situated within a valley and was surrounded by large hills. This topology would require wind-turbine systems to be placed large distances from the city proper, a feature which discounted wind-power. With respect to biomass, it was determined that biomass combustion systems would incur high costs and health/safety risks that were not present in other systems. Finally, hydropower which could be generated from a nearby stream, was not available in sufficient quantity to provide electricity for the entire village. Consequently, although hydroelectric power is one of the major sources of electricity in Uganda, it was not viable for the current project (Sengendo, 2001) When these considerations are taken together, the choice to proceed with a solar-power-based system was obvious.

Important to the project is the sustainability of the initiative and the reception of this new technology to the local residents. Technology reception has been shown to be a critical factor in the success of electrification projects of this nature.(Murphy, 2001).

\section{System Design}

Following the selection of solar-power as the source of electricity, it was possible to design a system which would simultaneously meet a number of divergent goals. Among those goals were: (1) sufficient and reliable power production, (2) robust design with an extended life, (3) simple maintenance and operation, and (4) low cost. A critical component in the design of the system was the assurance that its successful operation would continue long after the initial installation (10 years).

The first step in the design process was the assessment of the necessary power-production capability of the system. Typical power usage would occur for brief periods of time in the mornings and for more extended durations in the evenings. The number of light bulbs required for the entire project was 100. Each bulb is a CFL style, 7-Watt device. Our calculations allowed for approximately $50 \%$ of the bulbs to be used in mornings (for two hours) and $95 \%$ of the bulbs to be used in the evenings (up to five hours). Consequently, the expected power load is

Morning energy requirements

$$
\text { 50bulbs } \cdot 7 \text { Watts } \cdot 2 \text { hours }=700 \mathrm{~W}-\text { hrs }
$$

Evening energy requirements

$$
\text { 95bulbs } \cdot 7 \text { Watts } \cdot 5 \text { hours }=3325 \mathrm{~W}-\text { hrs }
$$

The total daily energy required for lighting is approximately $4000 \mathrm{~W}$-hrs. It is expected that approximately $1000 \mathrm{~W}-\mathrm{hr}$ of energy would be used each day through the outlets (powering handheld electronic devices), bringing the total energy required to approximately $5000 \mathrm{~W}$-hrs.

In order to meet the expected energy requirement, a modular system was designed. The system consists of two equally capable subsystems each designed to power one half of the entire village. The subsystems contained four 
175W solar panels, a Maximum Power Point Tracking system (MPPT), two 12V lead-acid batteries, an inverter, and a mechanical switch to allow power to be used only during evening and morning hours. The MPPT device optimized the efficiency with which the panels would charge the battery system, thereby increasing the efficiency of the overall system. One significant advantage of the selected village is that its close proximity to the equator (nearly coincident) meant that the variation of insolation during the year would be quite small and the system would effectively operate year round. Preliminary experiments indicate that the system is able to provide approximately 11,000 Watt-hours of energy each day, which exceeds the expected load by more than a factor of two. A schematic diagram of the solar-system is presented in Figure 1.

As shown in Figure 1, the inverter and a mechanical switch are located downstream of the battery pack. The mechanical switch was employed to activate the system only during the hours of 5-7 am and 7pm-midnight.

In total, 100 seven Watt bulbs were installed along the village. Each home was sufficiently small so that either one or two bulbs were sufficient for providing adequate light. An aerial view of the village is shown in Figure 3 . The image also shows the location of the solar-power systems and the trajectory of the two independent electrical lines. The location of the systems was dictated by land-availability and an agreement which was reached with the land owner. The total linear distance of the electrical lines was approximately $250 \mathrm{~m}$ and the total amount of wire which was used was approximately $2,000 \mathrm{~m}$.

\subsection{Design of Housing Structure}

I was important to ensure that the electronic components were safely contained within a structure so that threats of weather (moisture and elevated temperatures) could be mitigated and threats of theft could be avoided. In particular, exposure to moisture and elevated temperatures has the potential of causing catastrophic damage to the electronics (MPPT, batteries, inverter). Continued exposure to elevated temperatures is well known to reduce the effectiveness and lifetime of lead-acid batteries and reduce the hazards associated with their disposal (Sandgren, 2001). Consequently, the structure shown in Figure 3 was constructed. The figures show two views of the structure; in one view, a locally built doorway is visible. The structure was built with clay-covered bricks and air holes were included to help reduce temperatures within the structure by providing ventilation. The thick brick-clay composite walls were effective in lowering the maximum day-time temperatures because of their thermal inertia. The structure roof was fashioned from standard corrugated metallic sheets.

A metallic frame was built around the outside of the structure and extended over the roof. The frame was used to house the solar panels which, because of their positioning atop the structure, also provided shade to the structure. Around the exterior of the structure and frame, a chain-link fence was built for security and razor wire was installed atop the fence. The fence and razor wire is clearly evident from Figure 3.

Within the structure, a cement slab with shelving was used to help moderate internal temperatures, promote airflow past the electronic components, and ensure that the components did not rest near the ground where exposure to moisture was possible. The construction of the structure and the fence required approximately two days of manual labor and was completed using locally available materials.

\subsection{Wiring Details}

To provide some perspective on the wiring difficulty, it is appropriate to show images of typical residences which were afforded electricity. Figure 4 has been prepared to show a simple wiring schematic for three houses which are contained within a larger structure. It is seen that the wiring is performed in parallel and that circuit breakers are used at either end of the larger structures.

To provide a greater perspective of the installation conditions, photographical images are displayed in Figures 5 and 6 which are related to wiring activities outside and inside the houses, respectively. From Figure 5, it is seen that wire was strung along the front of houses, underneath a metal-corrugated roofing structure. Wire is passed into the house through a clay grate as seen on the right-hand side of the image. Wiring outside the houses took place at 6-12 feet of elevation so that rudimentary three-point ladders, like that shown in Figure 5, were essential. During the installation, care was taken to affix the main line to study supports underneath the corrugations. Those supports were formed by timbers, as seen in the figure. Further care was taken to ensure that the wiring was not exposed to potential future moisture and rain. Consequently, all wiring and switches were tucked into recesses in the roof structure. This approach also reduced the likelihood that residents, particularly children, would interfere with the wiring in the future.

The next figure, Figure 6 , shows the installation of wiring and light socket within a house. The photograph shows the underside of the corrugated roof with timber supports. The light is crudely hung freely from a perch passing through gaps between the timber and the sheet metal. While crude, this technique had a number of advantages. 
Specifically, it allowed the height of the bulb to be easily adjusted by the resident so that bulbs could be changed easily if one breaks. It also allowed some modification of the height of the light fixture so that the lighting conditions within the house could be tailored. The one-room house, shown in Figure 6, is typical of other houses throughout the village. A common size is approximately 20 square meters in footprint with a square base plan.

\subsection{Total Project Duration and Costs}

Seven persons completed the installation of the electronics, wiring, fixtures, and auxiliary components in approximately a one-week duration. The team consisted of two faculty members from the University of St. Thomas School of Engineering, four undergraduate students, and one graduate student. The wiring activities were basic and all participants contributed to that effort. On the other hand, installing and connecting the solar panels, battery systems, inverters, and mechanical switches was carried out by two more highly trained individuals (faculty member and graduate student).

The project costs are categories by equipment and travel expenses. Equipment, including solar panels, all associated electronics, wiring, fixtures, and equipment transportation totaled approximately $\$ 7000$. Airfare from the United States to Uganda, for each member of the installation team was approximately $\$ 1300$. Transportation costs within Uganda, was approximately $\$ 3000$. The total cost of the project was approximately $\$ 23000$.

The very low cost of this project has motivated studies to determine whether it can be replicated at other locations within Uganda and elsewhere in the East Africa region. There is a great potential that volunteer workers would be willing to fund their own travel expenses which would greatly lower the overall costs. It is believed that based on this experience, it is possible to replicate this successful system for approximately $\$ 10,000$.

\section{Concluding Remarks}

The work discussed in this report is a case study of a low-cost solar-powered electrical system that was designed and implemented to provide power for a very remote village with somewhat harsh circumstances. The system was built with a modular design including two identical power-generation system $\mathrm{s}$ to operate simultaneously. Replications of the system are expected to cost approximately $\$ 10,000$ (US) for similar sized systems (approximately 50 homes, a school, and a pharmacy). The anticipated energy output of the system is more than twice the expected load, thereby ensuring adequacy of the design. The conservative design will improve the sustainability of the system and will allow it to function effectively for a longer period of time. Under a conservative estimate, the system is expected to work effectively for 5-10 years. Periodic replacement of the lead-acid batteries will significantly extend the lifetime to $10+$ years.

\section{References}

Davidson, O., Halsnaes, K., Huq, S., Kok, M. (2003). The development and climate nexus: The case for sub-saharan Africa, Climate Policy, 3, S97-S113.

Kaijuka, E. (2006). GIS and rural electricity planning in Uganda, Journal of Cleaner Production, 15, 203-217, doi:10.1016/j.jclepro.2005.11.057

Karekezi, S. (2002). Poverty and Energy in Africa - A brief review, Energy Policy, 30, 915-919, doi:10.1016/S0301-4215(02)00047-2

Kammen, D., and Kirubi, C. (2008). Poverty, Energy, and Resource Use in Developing Countries, Annals of the New York Academy of Sciences, Vol. 1136, pp. 348-357, DOI: 10.1196/annals.1425.030

Murphy, J. (2001). Making the energy transition in rural east Africa: Is leapfrogging and alternative?, Technology Forecasting and Social Change, 68, 173-193, doi:10.1016/S0040-1625(99)00091-8

Sandgren, A. (2001). Batteries used within solar electric systems in rural Uganda, Makerere University Research Repository, Available: http://dspace.mak.ac.ug/handle/123456789/320

Sengendo, M. (2001). Photovoltaic project for rural electrification-Uganda, ENERGIA News, Available: http://www.energia.org/fileadmin/files/media/EN112001_sengendo.pdf

Sprei, F. (2002). Characterization of power system loads in rural Uganda, Lund University of Technology, M.S. Thesis.

Wolde-Rufeal, Y. (2006). Electricity consumption and economic growth: a time series experience for 17 African countries, Energy Policy, 34, 1106-1114, doi:10.1016/j.enpol.2004.10.008 


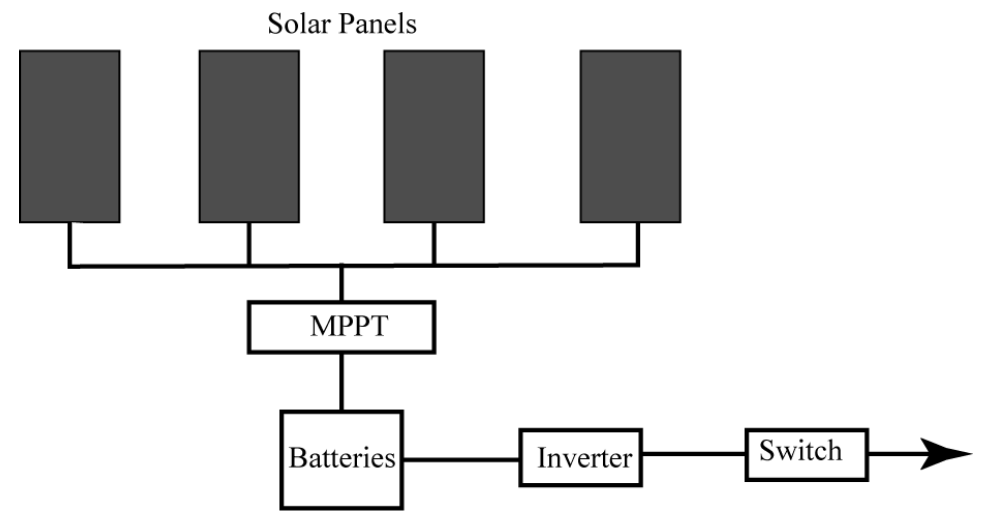

Figure 1. Schematic diagram showing electrical system used to power village

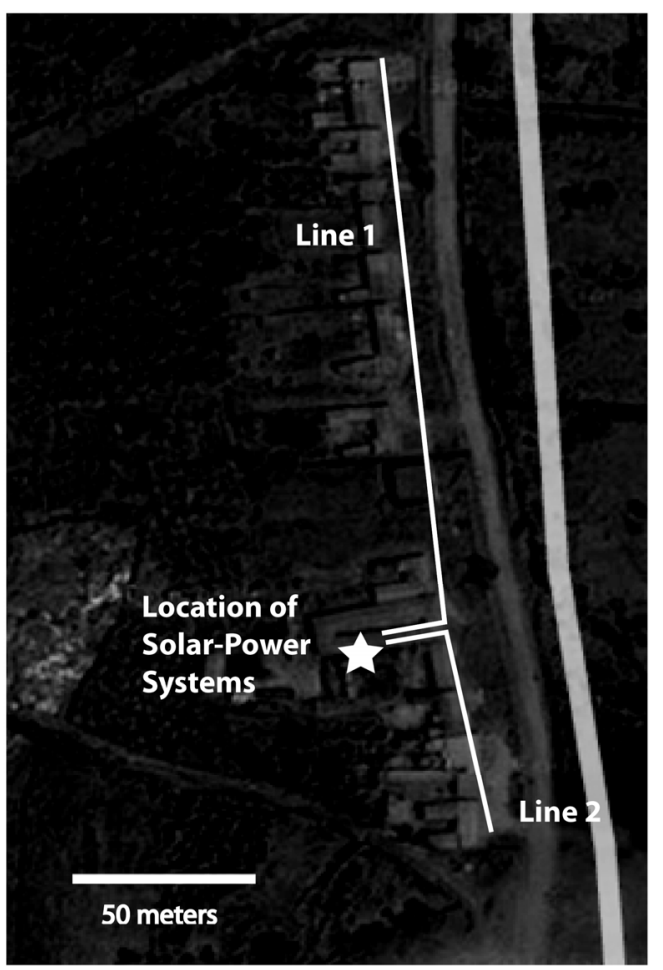

Figure 2. Aerial view of village and notation showing the location of the solar-power systems and the two separate electrical lines 


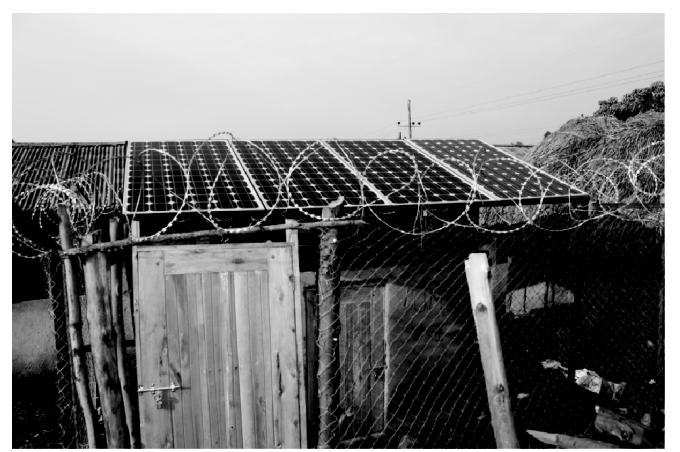

(a)

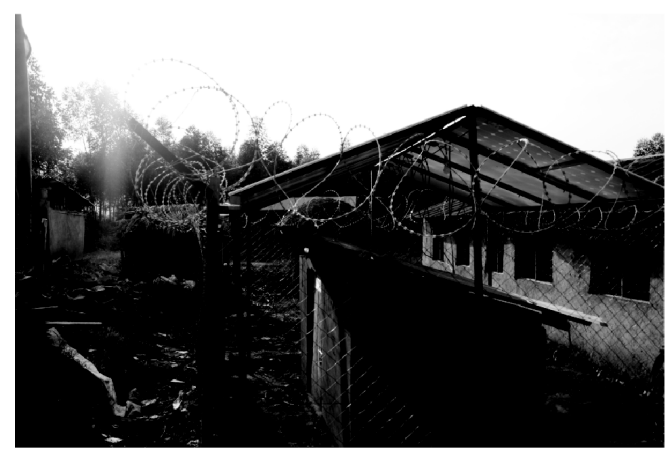

(b)

Figure 3. Two photographs showing the structure which was built to house electronic equipment

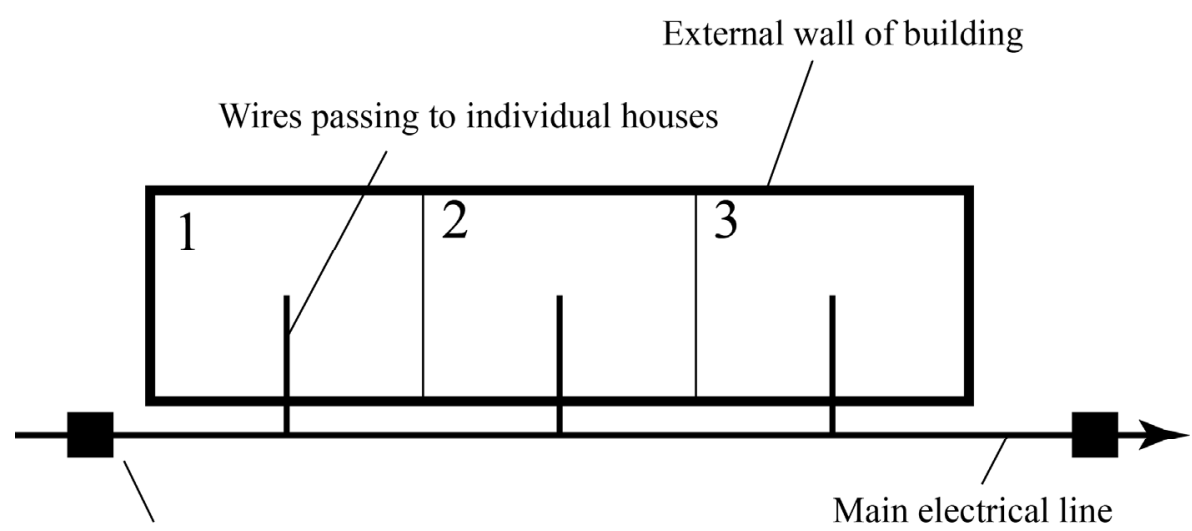

Breakers installed

intermittently along main line

Figure 4. Simplified wiring diagram showing a main line passing three houses $(1,2,3)$, all of which are contained within a larger building 


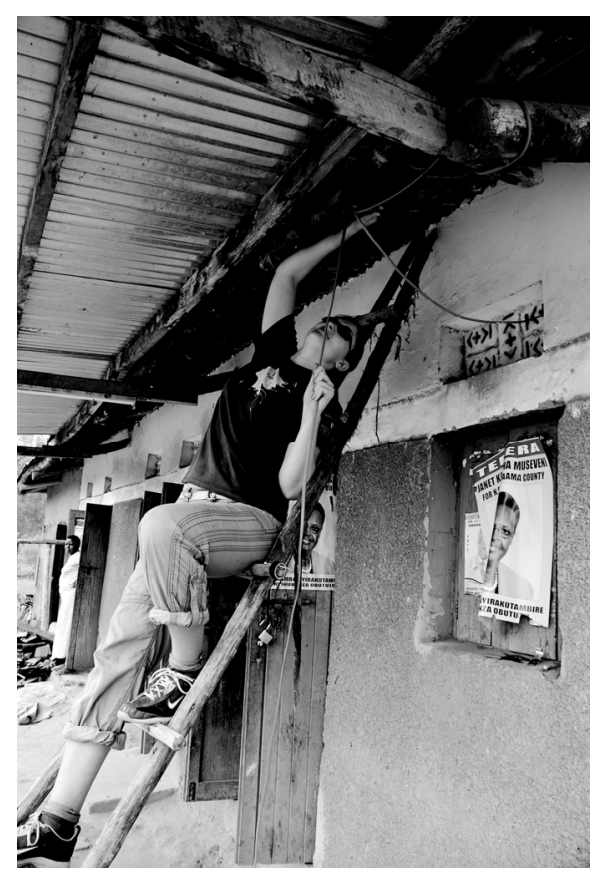

Figure 5. Photograph showing details of wiring outside of a typical village residence

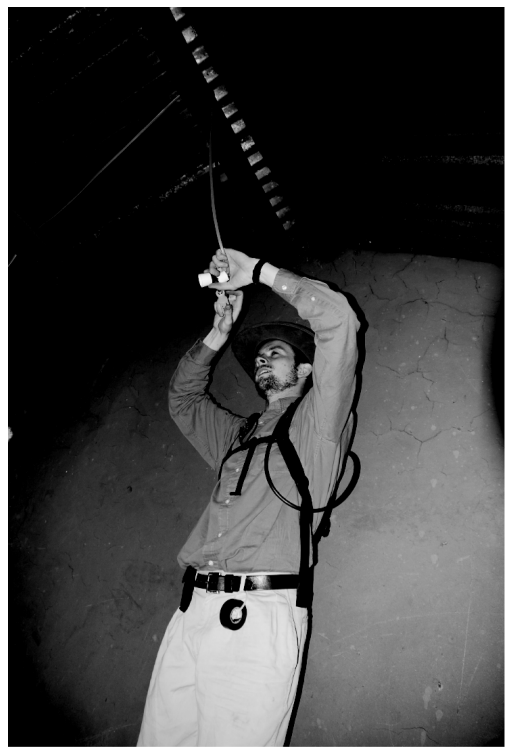

Figure 6. Photograph showing a light-fixture installation within a house 